\title{
CUIDADO ÀS MULHERES LÉSBICAS E BISSEXUAIS NA FORMAÇÃO EM ENFERMAGEM: PERCEPÇÃO DE DISCENTES
}

\author{
ELISABETA ALBERTINA NIETSCHE ${ }^{1}$ \\ ORCID: https://orcid.org/0000-0002-8006-2038 \\ TAIS TASQUETO TASSINARI ${ }^{2}$ \\ ORCID: https://orcid.org/0000-0001-9878-0938 \\ TIERLE KOSLOSKI RAMOS ${ }^{3}$ \\ ORCID: https://orcid.org/0000-0001-7901-3792 \\ CLÉTON SALBEGO 4 \\ ORCID: https://orcid.org/0000-0003-3734-9970 \\ SILVANA BASTOS COGO 5 \\ ORCID: https://orcid.org/0000-0002-1686-8459 \\ ANDREI POMPEU ANTUNES 6 \\ ORCID: https://orcid.org/ 0000-0003-1659-5670 \\ ALINE GOMES ILHA ${ }^{7}$ \\ ORCID: https://orcid.org/ 0000-0002-5715-9595
}

\begin{abstract}
RESUMO: No Sistema Único de Saúde (SUS), a integralidade é um dos princípios fundamentais, o que requer dos profissionais um melhor conhecimento da situação de saúde do usuário, considerando suas relações e seu histórico social, garantindo, assim, um acolhimento e um atendimento adequados e de qualidade. O usuário deve ser tratado de modo equânime e integral, inclusive sobre as questões que perpassam a identidade de gênero e orientação afetivo-sexual. Nesse sentido, este estudo busca analisar a percepção dos graduandos do curso de enfermagem quanto à sua formação para o cuidado de mulheres lésbicas e bissexuais. Trata-se de pesquisa qualitativa descritiva e exploratória. A coleta de dados ocorreu com 15 participantes, por meio de uma entrevista semiestruturada, no período de setembro a outubro de 2015. A análise e a interpretação estiveram embasadas na Análise de Conteúdo de Bardin. Os resultados
\end{abstract}

\footnotetext{
${ }^{1}$ Professora Titular do Departamento de Enfemagem da Universidade Federal de Santa Maria (UFSM). Santa Maria, RS, Brasil.<eanietsche@gmail.com>

${ }^{2}$ Doutoranda do Programa de Pós-Graduação em Enfermagem da Universidade Federal de Santa Maria (UFSM). Santa Maria, RS, Brasil. <taistasquetotassinari@gmail.com>

${ }^{3}$ Doutoranda do Programa de Pós-Graduação em Enfermagem da Universidade Federal de Santa Maria (UFSM). Santa Maria, RS, Brasil.<tierleramos@hotmail.com>

${ }^{4}$ Doutorando do Programa de Pós-Graduação em Enfermagem da Universidade Federal de Santa Maria (UFSM). Santa Maria, RS, Brasil.<cletonsalbego@hotmail.com>

${ }^{5}$ Professora Adjunta do Departamento de Enfemagem da Universidade Federal de Santa Maria (UFSM). Santa Maria, RS, Brasil. <silvanabastoscogo@gmail.com>

${ }^{6}$ Acadêmico do Curso de Graduação em Enfermagem da Universidade Federal de Santa Maria (UFSM). Santa Maria, RS, Brasil. <andrei.pompeuantunes@hotmail.com>

${ }^{7}$ Mestranda do Programa de Pós-Graduação em Enfermagem da Universidade Federal de Santa Maria (UFSM). Santa Maria, RS, Brasil.<aline.gomes1996@hotmail.com>
} 
organizaram-se em três categorias: influências da formação no cuidado prestado às mulheres lésbicas e bissexuais; potencialidades no cuidado às mulheres lésbicas e bissexuais com relação à formação acadêmica; fragilidades e alternativas acerca da formação no cuidado às mulheres lésbicas e bissexuais. Por fim, identificou-se a necessidade de ampliação da reflexão concernente ao tema na graduação, com o intuito de formar enfermeiros generalistas preparados e seguros para realizar o cuidado adequado a essas mulheres, atendendo suas especificidades.

Palavras-chave: Educação em Enfermagem, bissexualidade, homossexualidade feminina, gênero.

\section{CARE FOR LESBIAN AND BISEXUAL WOMEN IN NURSING EDUCATION: STUDENTS' PERCEPTION}

ABSTRACT: In the Unified Health System (SUS), integrality is one of the fundamental principles, which requires professionals to have a better knowledge of the user's health situation, considering their relationships and social history, thus ensuring a reception and adequate and quality care. The user must be treated in an equal and integral manner, including issues that permeate gender identity and affectivesexual orientation. In this sense, this study seeks to analyze the perception of undergraduate nursing students about their training to care for lesbian and bisexual women. This is a qualitative descriptive and exploratory research. Data collection occurred with 15 participants, through a semi-structured interview, from September to October 2015. The analysis and interpretation were based on Bardin's Content Analysis. The results were organized into three categories: influences of training in the care provided to lesbian and bisexual women; potentialities in the care provided to lesbian and bisexual women regarding academic training; weaknesses and alternatives about training in the care provided to lesbian and bisexual women. Por fim, identificou-sea necessidade de ampliação da reflexão concernente ao tema na graduação, com o intuito de formar enfermeiros generalistas preparados e seguros para realizar o cuidado adequado a essas mulheres, atendendo suas especificidades.

Keywords: Nursing Education, bisexuality, female homosexuality, gender.

\section{ATENCIÓN AS MUJERES LESBIANAS Y BISEXUALES EN LA FORMACIÓN DE ENFERMERÍA: PERCEPCIÓN DE LOS ESTUDIANTES}

RESÚMEN: En el Sistema Único de Salud (SUS), la integralidad es uno de los principios fundamentales, que requiere que los profesionales conozcan mejor a la situación de salud del usuario, considerando sus relaciones y su historia social, garantizando así una acogida adecuada y servicio de calidad. El usuario debe ser tratado de manera equitativa e integral, incluso en cuestiones que involucran la identidad de género y la orientación afectivo-sexual. En este sentido, este estudio busca analizar la percepción de los estudiantes de enfermería de pregrado sobre su formación para el cuidado de mujeres lesbianas y bisexuales. Se trata de una investigación cualitativa descriptiva y exploratoria. La recolección de datos fue hecha con 15 participantes, a través de una entrevista semiestructurada, de septiembre a octubre de 2015. El análisis y la interpretación se basaron en el Análisis de Contenido de Bardin. Los resultados se organizaron en tres categorías: la formación influye en la atención brindada a mujeres lesbianas y bisexuales; potencialidades en el cuidado de mujeres lesbianas y bisexuales en relación a la formación académica; y debilidades y alternativas en la formación en el cuidado de mujeres lesbianas y bisexuales. Finalmente, se identificó la necesidad de ampliar la reflexión sobre el tema en investigado, a fin de formar enfermeras generalistas que estén preparadas y seguras para brindar una atención adecuada a estas mujeres, tomando en cuenta sus especificidades.

Palabras clave: Educación en Enfermería, , bisexualidad, homosexualidad femenina, género. 


\section{INTRODUÇÃO}

No Sistema Único de Saúde (SUS), a integralidade é um dos princípios fundamentais, o que requer dos profissionais um melhor conhecimento da situação de saúde do usuário, considerando suas relações e seu histórico social, garantindo, dessa forma, um acolhimento e um atendimento adequados e de qualidade. Um aspecto da integralidade refere-se ao "ato de cuidar integral que tem as práticas de saúde como eixos políticos-organizativos, formas de construir inovações e novas tecnologias de atenção aos usuários no SUS” (PINHEIRO, 2008 p. 260). O preâmbulo do Código de Ética dos Profissionais de Enfermagem afirma que o respeito aos direitos humanos, enquanto princípio fundamental, é inerente ao exercício profissional. Além dos diretos à vida, à saúde, à liberdade e à igualdade, a pessoa deve ser tratada sem distinções, incluindo-se a distinção de gênero e orientação sexual. $\mathrm{O}$ artigo 41 ainda discorre sobre o dever profissional de "prestar assistência de Enfermagem sem discriminação de qualquer natureza”(COFEN, 2017).

No entanto, ainda existe fragilidade quanto a essa assistência no que diz respeito a algumas temáticas, destacando-se a sexualidade humana. Esta última envolve processos culturais e plurais, concepções e definições históricas que produzem e transformam a natureza e a biologia. Assim, "as possibilidades da sexualidade - das formas de expressar os desejos e prazeres - também são sempre socialmente estabelecidas e codificadas" (LOURO, 2018, p.3). Nesse sentido, o tema da sexualidade ainda é impregnado de tabus e preconceitos, que perpassam tanto a formação acadêmica quanto a prática profissional. Outrossim, velar esse assunto pode consistir em um mecanismo gerador de ansiedades, incertezas e constrangimentos mútuos. No contexto das relações interpessoais, os temas relacionados à sexualidade geram, na maioria das vezes, desconforto por parte dos interlocutores, em especial quando o assunto é a diversidade sexual e de gênero (VITIRIT'TI; ANDRADE; PERES, 2016).

Considerando a cultura heteronormativa da sociedade, trazendo a heterossexualidade como norma, evidencia-se que o preconceito contra a diversidade sexual se manifesta por meio de fatores interacionais que desqualificam sexualidades, identidades, comportamentos e comunidades não heterossexuais, demarcando grupos sociais e valorando diferentemente esses grupos e seus membros (COSTA; NARDI, 2015). Em vista disso, a população LGBTQIA ${ }^{8}$, ao longo dos anos, tem seus direitos constantemente negligenciados em diversos âmbitos do contexto social: saúde, educação, lazer, moradia, dentre outros (SILVA et al., 2017). Assim, observa-se que homens e mulheres que não seguem o modelo estabelecido sofrem preconceitos e discriminações pela sociedade. Frente a esse contexto, constata-se a necessidade de os profissionais de saúde, especificamente enfermeiros, estarem capacitados para atender a essa população sem discriminá-la, visando à qualidade do cuidado.

As construções que envolvem a sexualidade naturalizam a heterossexualidade normativa, de modo que esta pareça inevitável. As mulheres lésbicas e bissexuais evidenciam uma sexualidade que não atende aos padrões de comportamento sexual definidos pela heterossexualidade (BUTLER, 2017). Desse modo, esta população torna-se mais vulnerável a preconceitos e estigmas relacionados à sua orientação sexual e necessita, pois, de cuidados adequados nos serviços de saúde. Entretanto, verifica-se que a assistência fornecida pelos profissionais da saúde, em sua maioria, não é adequada, com destaque para a interação entre os profissionais e as mulheres, a abordagem de temas relacionados à sexualidade e o estabelecimento do vínculo profissional-usuário (ARAÚJO et al., 2019).

A homossexualidade feminina é um tema emergente no contexto de atuação em saúde, impondo-se como imprescindível discussão na formação do profissional da área, destacando-se, neste estudo, o enfermeiro. Desse modo, espera-se constituir a formação de profissionais capacitados para o atendimento efetivo e integral a essas mulheres. Portanto, as instituições de ensino em enfermagem devem contemplar uma formação que forneça informações acerca da população LGBT e, mais especificamente, sobre lésbicas, a fim de prevenir para que não haja preconceito contra este grupo e também como forma de abordar necessidades específicas de cuidados de saúde (PINTO; NOGUEIRA, 2016).

\footnotetext{
${ }^{8}$ A partir de 2008 passou a ser utilizada no Brasil a sigla LGBT para identificar a ação política e conjunta de Lésbicas, Gays, Bissexuais, Travestis, Transexuais. Atualmente há a inclusão de variações a essa sigla para designar outros movimentos e identidades em construção (Intersexos, Queer, Assexuais ou mesmo um sinal de + ). Considerando que a inclusão de variações é recente, utilizaremos ao longo do texto a sigla LGBT conforme apresentado nos documentos consultados. Educação em Revista|Belo Horizonte|v.38|e26442|2022
} 
Um avanço recente que inclui a população de mulheres lésbicas e bissexuais, em questões de saúde, ocorreu em 2010, quando o Ministério da Saúde lançou a Política Nacional de Saúde Integral de lésbicas, gays, bissexuais, travestis e transexuais, de caráter transversal, contemplando a produção do conhecimento, a participação social, a promoção, a atenção e o cuidado. Essa política possui diretrizes relacionadas à inclusão de temas como orientação sexual e identidade de gênero nos processos de educação permanente desenvolvidos pelo SUS, bem como estímulo à produção de conhecimento científico que vise à melhoria das condições de saúde da população LGBT (BRASIL, 2013). Para este estudo, serão utilizados os conceitos de "homossexual" e "bissexual" dispostos no Manual de Comunicação LGBT da Associação Brasileira de Lésbicas, Gays, Bissexuais, Travestis e Transexuais. O manual considera como homossexual "a pessoa que se sente atraída sexual, emocional ou afetivamente por pessoas do mesmo sexo/gênero" (REIS, 2018, p. 22), e bissexual "a pessoa que se relaciona afetiva e sexualmente com pessoas de ambos os sexos/gêneros" (Ibidem, p. 21).

Tendo em vista que o enfermeiro deve estar apto a prestar o cuidado com igualdade, equidade e ética, observou-se a necessidade de que o processo formativo em enfermagem propicie subsídios para o cuidado das mulheres lésbicas e bissexuais. Diante do exposto, este estudo apresenta como questão norteadora a seguinte reflexão: qual a percepção de graduandos de enfermagem quanto à sua formação para o cuidado a mulheres lésbicas e bissexuais? Assim, este artigo objetiva responder tal questionamento e identificar as potencialidades e fragilidades encontradas nas práticas acadêmicas dos graduandos de enfermagem.

\section{MÉTODO}

Trata-se de uma pesquisa qualitativa descritiva e exploratória (POLIT; BECK, 2019). O cenário do estudo foi o curso de enfermagem de uma Universidade Federal do interior do estado do Rio Grande do Sul. Foram incluídos no estudo discentes do curso de enfermagem matriculados em 2015.2, na disciplina "Estágio Supervisionado I", referente ao $7^{\circ}$ semestre de curso. Destaca-se que nesse período os discentes já estão inseridos nos serviços de saúde, realizando o Estágio Curricular Supervisionado, vivenciando a prática do profissional enfermeiro. Os discentes matriculados em disciplinas do $8^{\circ}$ semestre não foram considerados em razão de a pesquisadora fazer parte da turma de discentes, evitandose, assim, conflitos de interesses, constrangimentos e possíveis fragilidades do estudo. Foram excluídos aqueles que estavam afastados da universidade devido a atividades de intercâmbio, atestados e/ou tratamentos. Também foram excluídos os participantes do grupo de estudos e pesquisa do qual a pesquisadora fazia parte, visto que tiveram acompanhamento direto de sua construção e execução. A população deste estudo contemplou um total de 19 discentes, sendo que quatro deles foram excluídos por terem tido acesso ao projeto por meio de grupos de pesquisa. Assim, a amostra final do estudo totalizou 15 participantes, os quais foram familiarizados com os objetivos da pesquisa.

A coleta dos dados ocorreu no período de setembro a outubro de 2015, utilizando-se a técnica de entrevista semiestruturada (POLIT; BECK, 2019), que contemplou questões relativas à caracterização dos participantes, à abordagem, ao preparo e à influência da graduação em enfermagem no cuidado a mulheres lésbicas e bissexuais, bem como à vivência/realização de cuidado a mulheres lésbicas e bissexuais ao longo da formação e aos fatores positivos e negativos identificados durante a graduação relacionados à temática. As entrevistas foram agendadas, e a coleta foi realizada individualmente, na instituição de origem, em local combinado com cada participante, buscando promover um cenário que proporcionasse conforto e privacidade aos participantes. Dentre os locais, citam-se: sala de aula pertencente ao Departamento de Enfermagem da instituição, reservada previamente para as entrevistas; e sala específica disponibilizada pelo Hospital Universitário da instituição, em decorrência de alguns acadêmicos preferirem agendar as entrevistas em horário próximo ao de estágio. As entrevistas foram gravadas em equipamento de multimídia player, sendo ouvidas atentamente, transcritas na íntegra, digitadas e formatadas em documento do Microsoft Word versão 2007, compondo o banco de dados do estudo. As transcrições foram identificadas alfanumericamente pela letra D, referente à "discente", e numeradas conforme a sequência de realização da coleta dos dados.

Para a análise dos achados, prosseguiu-se às etapas preconizadas pela análise categorial temática, que recomenda operações de desmembramento de um texto em unidades e categorias, de 
acordo com reagrupamentos analógicos. Dentre as diferentes formas de categorização, a investigação por meio de temas é considerada eficaz e rápida no caso de discursos simples e diretos. Foram seguidas as seguintes etapas: pré-análise, exploração do material, tratamento dos resultados, inferência e interpretação (BARDIN, 2016).

Na pré-análise, houve leitura flutuante dos achados e apropriação inicial do conteúdo, com posterior seleção das partes mais relevantes ao objetivo da pesquisa para a constituição do corpus do trabalho, por meio dos critérios de representatividade, homogeneidade e pertinência (BARDIN, 2016). Ao fim dessa etapa, os dados selecionados foram editados para a análise. A segunda etapa esteve permeada por operações de decomposição, visando à definição de categorias, por meio do recorte dos núcleos de sentido nas falas dos participantes, que conferiram significado aos aspectos analisados no estudo. Assim, as transcrições continham grifos destacando as partes relevantes, posteriormente copiadas para outro arquivo. $\mathrm{Na}$ última etapa, os dados selecionados receberam tratamento de modo a serem válidos e significativos. Dessa maneira, foram realizadas inferências e interpretações no intuito de destacar as principais informações encontradas na pesquisa e expô-las de forma clara (BARDIN, 2016).

Após a análise final, a aplicação dessa técnica permitiu a construção de três categorias analíticas, a saber: influências da formação no cuidado às mulheres lésbicas e bissexuais; potencialidades no cuidado às mulheres lésbicas e bissexuais com relação à formação acadêmica; e fragilidades e alternativas acerca da formação no cuidado às mulheres lésbicas e bissexuais.

A pesquisa cumpriu os dispositivos e as orientações no que se refere à realização de estudos com os seres humanos, consoante aos princípios da bioética do Comitê de Ética em Pesquisa (CEP) da Universidade Federal de Santa Maria (UFSM), tendo sido aprovada em 14 de agosto de 2015, sob parecer número 1.181.419 e CAAE: 47531915.3.0000.5346.

\section{RESULTADOS}

Quanto à caracterização dos participantes, 12 eram do sexo feminino e três eram do sexo masculino. A idade variou entre 20 e 33 anos. Quanto ao grau de escolaridade, dois possuíam curso técnico de enfermagem, atuando como profissionais. Um participante possuía curso técnico em montagem e manutenção de computadores, uma em contabilidade e outra participante já cursou graduação em psicologia, sem concluir o curso.

\section{Influências da formação no cuidado às mulheres lésbicas e bissexuais}

Os participantes foram indagados acerca da vivência/realização ou observação de atendimento a mulheres lésbicas e/ou bissexuais durante as práticas curriculares desenvolvidas na graduação. Diante de tal experiência, buscou-se pontuar as limitações identificadas durante esses atendimentos. Além disso, procurou-se conhecer a influência da formação diante dessas situações.

Quanto ao objeto em estudo, estão apresentadas, nos depoimentos a seguir, as percepções dos discentes que acreditam não terem atendido essa população, bem como suas visões de como seria o desenvolvimento do cuidado. Também foram relatadas as experiências daqueles que realizaram atendimentos a mulheres lésbicas e bissexuais.

[...] questão de atendimento, acho que vai ser o mesmo como eu ia atender as outras pessoas, os outros pacientes, são todos iguais. Eles diferem de orientação sexual. Em questão de atendimento é igual (D12).

[...] foi tranquilo. No início tu gera um desconforto, como tu vai tratar aquela pessoa... Eu acho que não é só o preconceito que a gente tem com eles, mas que eles também, de tanto sofrerem com isso, eles acabam ficando meio limitados. Mas na maioria das vezes é completamente normal, não tem nenhuma diferença, não tive nenhum problema. [...] É uma pessoa que está precisando de determinado cuidado, como qualquer outro. Quando a gente parte do pressuposto que deveria ter algum meio diferente de cuidar esse tipo de pessoa aí sim que vai gerar preconceito e a gente vai acabar ficando nervoso na hora de atender. (D4)

Eu não tenho preconceito, eu sou bem despida disso. Me senti tranquila [...] preparada, sem problemas. [...] é uma pessoa normal. Independente da opção sexual dela, ela tem sentimentos, 
problema como qualquer outra pessoa, ela é uma pessoa normal. Iria atender da mesma maneira que eu atenderia qualquer outra pessoa. Já que a gente, amanhã ou depois é futuro profissional da saúde e vai atender os mais né... Diferentes contextos, diferentes gêneros e a gente tem que respeitar (D1).

Com relação às limitações identificadas durante o atendimento a mulheres lésbicas ou bissexuais, discorrem os depoimentos a seguir:

Se existir alguma demanda específica para um paciente homossexual talvez eu não soubesse lidar, porque eu não sei se existe realmente alguma demanda específica. [...] eu acho que eu teria que me preparar, com relação às orientações de cunho sexuais e de gênero. [...] eu me prepararia da maneira em buscar estudos e, literalmente, correr atrás pra saber como atender esse paciente. $\mathrm{E}$ não deixar de atender, jamais (D2).

[...] sobre, a dificuldade de prestar o cuidado e a gente não ter o embasamento, de como cuidar. De como se portar diante de um paciente homossexual, a gente não tem uma base. [...] como abordar, como chegar ao paciente pra que ele não se sinta ofendido, pra que ele se sinta bem cuidado (D8).

Os participantes também foram questionados acerca da influência da graduação nos atendimentos a essa população. Ao mesmo tempo que houve participantes que não identificaram influências da formação para o cuidado a este público, outros abordaram que o ingresso na universidade, bem como a graduação em enfermagem, apresentam influência direta nesse contexto:

Eu acho que da graduação não, é como se tivesse cuidando de qualquer outra pessoa, normal. $\mathrm{Eu}$ acho que todo mundo que trabalhou com homossexuais, vem meio de casa, como tu é educada, como é na tua família abordado esse tema (D4).

Eu acho que vai mais da pessoa, a graduação não colaborou muito com isso. Eu acho que vai muito da nossa criação, do que a gente acredita, porque na graduação foi tratado pouco (D7).

[...] acho que dá para dizer que sim, que tem influência sim. Antes da academia [graduação em enfermagem] eu era uma pessoa mais preconceituosa [...] depois que eu entrei na graduação eu comecei a ter uma evolução no meu pensamento, eu tive uma abertura maior da mente (D11).

[...] a graduação te dá um respaldo, como eu vou te dizer, eu estou fazendo enfermagem então se ela me perguntar alguma coisa relacionada à saúde eu vou saber porque eu aprendi. Mesmo que eu não tenha tido nenhuma aula que falasse sobre mulheres homossexuais (D10).

[...] a gente procede de acordo com aquilo que teve em sala de aula. Então acredito que teria influência sim (D3).

Eu acho que tudo que é visto em teoria a gente pode aplicar para todo tipo de público que a gente vê (D9).

\section{Potencialidades no cuidado às mulheres lésbicas e bissexuais com relação à formação acadêmica}

Os participantes foram questionados a respeito das potencialidades para o cuidado às mulheres lésbicas e bissexuais, relacionadas, preferencialmente, à formação acadêmica. Assim, emergiram as seguintes falas:

[...] essa questão de eu não ter esses pré-conceitos que existem e, são fortes ainda, hoje em dia. [...] essa questão de você estar aberto a novas experiências, a saber lidar com isso, eu acho que isso facilita bastante (D2).

[...] isso que eu falei sobre a diversidade, a gente trabalha com diferentes populações, diferentes necessidades, eu acho que isso é um ponto positivo, que colabora (D7).

[...] a gente ser despido de todo esse preconceito, não ter medo ou vergonha de atender aquela pessoa (mulher homossexual ou bissexual) (D15).

Educação em Revista|Belo Horizonte|v.38|e26442|2022 
Nos questionamentos acerca das potencialidades para o cuidado a mulheres lésbicas e bissexuais, há discursos em que os participantes mencionam a ética do profissional enfermeiro:

[...] a questão que pelo menos sempre foi trabalhada, da gente atender sem nenhuma distinção, sem nenhum preconceito, sem nenhum julgamento pessoal. Eu acredito que isso me marcou, sempre foi enfatizado (D3).

[...] o que a gente discute sempre é a ética, a humanização, a singularidade de tratar ele como único, acho que isso é sempre positivo quando a gente vai tratar de um paciente (D9).

[...] a positiva que trouxe, eu acho que é a questão de ética, questão de respeito. [...] foi trabalhado na graduação a questão de atender todos, independente de orientação sexual, de condição socioeconômica, independente de qualquer demanda. Isso foi aprendido, a respeitar o outro, a ser ético, isso eu acho que seria um ponto positivo que é trazido muito (D12).

\section{Fragilidades e alternativas acerca da formação no cuidado a mulheres lésbicas e bissexuais}

Os participantes foram questionados acerca de possíveis fragilidades no cuidado às mulheres lésbicas e bissexuais, relacionadas, preferencialmente, à sua formação acadêmica. Nesse sentido, seguem os relatos abaixo:

[...] eu acho que a gente teria que adentrar mais nesse assunto (homossexualidade e bissexualidade feminina). Acho que precisa se falar mais sobre [na graduação] (D1).

[...] se tem uma coisa que foi negativa, que não foi favorável, é ter demorado tanto para ver a questão de gênero e sexualidade na graduação, ter sido tarde, bem dizer para o final da graduação (D2).

[...] tem muitos homossexuais que utilizam hormônios, terapia hormonal. Eu não saberia, por exemplo, orientar um homossexual que chegasse na unidade básica. [...] a saúde delas (mulheres homossexuais e bissexuais) não é vista, é como se elas não precisassem fazer preventivo, não precisassem fazer o autoexame das mamas, fazer a mamografia. Esse tipo de abordagem é muito difícil. [...] falta preparo para orientar. E a gente quase não vê nas unidades básicas porque as pessoas têm medo de serem julgadas e olhadas diferente, e têm pessoas que olham mesmo! (D3).

[...] acho que aulas falando sobre isso (homossexualidade e bissexualidade feminina), discussões em sala de aula, fazer uma roda de conversas; cada um relatar alguma coisa pode ajudar bastante! (D14).

Ainda com respeito às fragilidades para o cuidado a mulheres lésbicas e/ou bissexuais, os discentes de enfermagem falaram sobre o preconceito social e cultural. Quando este se faz presente em nosso meio, pode ser um fator prejudicial para o cuidado:

[...] o que pode prejudicar é realmente o preconceito que a gente tem às vezes, quando aborda, conversa com pessoas assim (homossexuais/ bissexuais). Eu acho que essa questão de, quando a gente tem alguma dificuldade de comunicação, de tentar entender o que está acontecendo (D4).

[...] ainda se tem muito preconceito com homossexuais, e talvez isso impeça da gente conversar mais sobre o assunto, apesar de hoje em dia ter melhorado um pouco (D11).

[...] é que se tem medo de discutir essas coisas porque o preconceito é muito grande, é como se fosse feio falar sobre isso (homossexualidade e bissexualidade feminina) (D15).

Os participantes foram questionados quanto às possíveis alternativas para a diminuição das fragilidades encontradas no cuidado às mulheres lésbicas e bissexuais. Nesse âmbito, citaram mudanças no ensino, bem como busca pessoal do conhecimento acerca do tema:

Precisa, primeiro de tudo a gente quebrar esse tabu que é conversar sobre homossexualidade. [...] é primordial que a gente discuta isso em sala de aula, porque quando tu estás fazendo um 
curso de graduação tu tem que ampliar o teu conhecimento. A gente precisa ter contato com isso antes do sexto semestre. Precisaria ter um espaço pra trabalhar isso dentro da nossa grade curricular (D1).

[...] uma opção em (re)alocar esse tema ou abordar ele de uma maneira diferente em semestres mais iniciais.[...]por mim podia ser lá nos básicos, como uma DCG(Disciplina Complementar da Graduação) [...] ser abordado mais no início da graduação. [...] poderia ser de maneiras que tragam os próprios homossexuais para estar falando um pouco da sua convivência, como é o dia a dia, a questão da aceitação na sociedade (D2).

Tem coisas que tu tem que buscar, ir atrás pra conseguir conhecimento (D6).

[...] é uma coisa que se tu quer saber mais, aprender como lidar, é uma busca pessoal, não precisaria se trabalhar isso no curso, porque se o cuidado é com a pessoa em si, não tem necessidade de ter esses cuidados específicos (D13).

\section{DISCUSSÃO}

Conforme os depoimentos analisados, observou-se que, a partir dos contatos realizados pelos discentes de enfermagem com mulheres lésbicas ou bissexuais, não houve experiências conflitantes, tendo em vista que apontam a aceitação dessa população na sociedade e a ausência de preconceito. Os discentes relataram uma abordagem generalista, situando o usuário como prioridade, desenvolvendo o cuidado sob uma perspectiva de integralidade, em que a condição sexual não interfere no cuidado de Enfermagem. Constatou-se a ausência de distinção entre as usuárias, bem como a preocupação em tratálas com respeito. Dados semelhantes revelaram que estudantes de diferentes cursos da área da saúde não sentiram desconforto durante o atendimento a usuários de qualquer condição sexual (GREENE et al., 2018).

Em contraponto, alguns relataram a falta de preparo para a realização do cuidado de mulheres lésbicas e bissexuais. Destacaram a dificuldade no acolhimento e o medo de não atenderem as usuárias de forma adequada, devido às singularidades de sua condição sexual. Em pesquisa com estudantes de medicina, a fim de identificar o conhecimento sobre usuários LGBT, houve relatos de falta de conhecimento para a prestação de cuidados a esse público (NAMA et al., 2017). Os autores ainda alertaram quanto à necessidade de mudança no nível de conhecimento dos estudantes para este tema. Frente ao apresentado, essa fragilidade formativa também pode ser percebida em nossa realidade local, em que os discentes se sentem, por vezes, despreparados para o cuidado a esse público, revelando sentimentos como medo e receio na abordagem a mulheres lésbicas ou bissexuais (NAMA et al., 2017).

De acordo com as Diretrizes Curriculares Nacionais (2001) para os cursos de Graduação em Enfermagem, o perfil do formando egresso deve incluir a "capacidade de atuar, com senso de responsabilidade social e compromisso com a cidadania, como promotor da saúde integral do ser humano" (BRASIL, 2001). Destarte, identifica-se a necessidade de sensibilizar e reforçar a formação acerca da sexualidade e diversidade de gêneros, nas suas diferentes formas de expressão, contextualizando-a na prática, de uma forma natural, sem preconceitos e dificuldades e contemplandoa, ainda, como mais um contributo para melhorar a qualidade de cuidados de enfermagem prestados à população - eis a grande meta desta reflexão (CARTEIRO; NENE, 2015).

Trabalhar a sexualidade vai além do conhecimento obtido pela internet, por livros, no contexto familiar, pela própria experiência de vida ou pela atitude de centralizar a questão apenas em aspectos orgânicos e patológicos: é nessa perspectiva que surge a necessidade de avanço na enfermagem, em discussões que abordem a sexualidade em suas diferentes etapas do ciclo de vida. O conhecimento sobre sexualidade é fundamental para a qualidade da assistência e do cuidado ao paciente/cliente. Durante a formação, é importante que o estudante adquira esse conhecimento nas aulas práticas e em estágios, construindo uma visão holística em seus aspectos sociais, de direitos e orientações sobre o autocuidado, e que trabalhe intervenção em saúde sexual (FIGUEIROA et al., 2017).

Observou-se domínio do que é trabalhado na graduação durante os cuidados realizados com mulheres lésbicas e/ou bissexuais, relacionando o conteúdo teórico às suas práticas. Assim, uma vez que as temáticas da homossexualidade e bissexualidade feminina são pouco discutidas em sala de aula, o cuidado a essas usuárias pode se tornar fragilizado. 
O profissional de enfermagem deverá estar despido de preconceitos e conceitos para atender de forma equânime a essas mulheres e desenvolver uma assistência que viabilize a proteção e promoção da sua saúde (FREITAS; SOUZA; ARAÚJO, 2015). Uma formação acadêmica que abarque discussões voltadas ao grupo LGBT pode apresentar efeitos positivos, uma vez que corrobora os conhecimentos, as habilidades e as atitudes dos profissionais e alunos, promove a competência cultural e a sensibilidade, reduzindo assim as dificuldades na abordagem dos atendimentos (BELÉM et al., 2018).

Os participantes identificaram, como potencialidade para o atendimento, a facilidade pessoal de aceitação da diversidade sexual e de gênero, de forma a assentir e a entender sem julgamentos pessoais ou preconceitos. $O$ fato de estar em contato com essas usuárias também foi mencionado como facilitador para o cuidado, por haver um maior conhecimento e uma maior familiaridade com essa população. Um estudo realizado com este mesmo objeto concluiu com unanimidade a respeito da importância da disciplina de bioética na formação e no desenvolvimento moral e ético do estudante (SOUSA et al., 2011). Frente a isso, os cursos de graduação em enfermagem devem se responsabilizar por assegurar uma formação ética e bioética satisfatória aos acadêmicos, de modo que estejam aptos para as discussões sobre cidadania, humanização, respeito às diversidades e à individualidade de cada ser (GREENE et al., 2018; NAMA et al., 2017).

Assim, percebe-se que, na instituição em que foi realizado este estudo, os discentes identificam o tema como uma potencialidade para o cuidado, enfatizando sua importância, o que é entendido como reflexo de um ensino adequado e de qualidade. De modo geral, a graduação em enfermagem tem como objetivo formar profissionais de enfermagem generalistas, com preparação científica, humana e capacitação suficiente para avaliar, identificar e implementar as necessidades de saúde e cuidados de pessoas saudáveis ou doentes, das famílias e da comunidade (ORTEGA et al., 2015).

Devido à complexidade do tema, evidencia-se a difícil tarefa encontrada pelos professores ao ministrar uma disciplina de tamanha relevância para a construção do pensamento crítico dos discentes. Ressalta-se que as dificuldades para trabalhar com o tema homossexualidade ocorrem pela limitação de abordagem na formação acadêmica e por questões particulares a cada indivíduo ou grupo social (FREITAS; SOUZA; ARAÚJO, 2015). Considerando que se trata de uma temática permeada de fatores histórico-culturais e complexa, há a necessidade de tempo e espaço dentro do cenário formativo para apreensão e familiarização deste assunto por parte dos discentes, com vistas ao desenvolvimento de um cuidado pautado na singularidade e individualidade.

$\mathrm{Na}$ formação acadêmica, ao abordar o tema sexualidade, as discussões que surgem acabam por identificar preconceitos e tabus, muitas vezes percebidos pelos silêncios, pela recusa de informações e pelo desconhecimento (SOUSA, 2015).

A graduação deve oferecer este espaço de discussão e aprofundamento acerca da temática, com suporte teórico-prático; a importância de renovar conceitos e valores quanto às lésbicas reflete-se diretamente no atendimento e na atenção integral de qualidade no processo de cuidado (CARTEIRO; NENE, 2015).

Também foi mencionada a invisibilidade da saúde das mulheres homossexuais e bissexuais e, concomitante a isso, a falta de preparo para trabalhar com essas situações de atendimento, permeadas por dúvidas e insegurança. $O$ atendimento às mulheres lésbicas é, muitas vezes, fragmentado e descontextualizado, pois não aborda sua orientação sexual, assistindo-as indiferentemente como heterossexuais (FREITAS; SOUZA; ARAÚJO, 2015).

Além das fragilidades em âmbito acadêmico, o preconceito intrínseco na sociedade e a questão cultural foram mencionados como fatores que influenciam na fragilidade do cuidado, sendo também responsáveis pela escassez de discussões sobre o tema em sala de aula. Os enfermeiros inseridos em um contexto sociocultural que tende a reprimir o tema da sexualidade absorvem a influência de crenças, mitos e tabus existentes, condicionando sua abordagem de forma natural (CARTEIRO; NÉNÉ, 2015).

Ocorre, ainda, a persistência de preconceito e desinformação a respeito de temas envolvendo a sexualidade, o que gera consequências em diferentes níveis. Um fator agravante é percebido quando o preconceito e a discriminação se fazem presentes em áreas responsáveis pela promoção da saúde, da garantia dos direitos humanos e do bem-estar da população - como é o caso da área da saúde e, mais especificamente, da enfermagem. A promoção, a prevenção e a reabilitação em saúde existem diante de 
qualquer sujeito; no entanto, devem-se levar em conta suas especificidades, o que necessariamente torna obrigatório que se atue sob os princípios da integralidade, da equidade, da universalidade e da humanização (FIGUEIROA et al., 2017).

Os discentes sentem a necessidade de uma discussão mais abrangente acerca da homossexualidade e bissexualidade feminina durante a sua formação acadêmica, enfatizando o pouco contato com o tema. Entre as alternativas para minimizar as fragilidades, mencionou-se a necessidade de abordar a homossexualidade como um todo, não apenas como um conceito, mas em seu histórico de lutas e seus pontos de vista. Desse modo, surge a possibilidade de trazer pessoas homossexuais para a sala de aula, com a finalidade de relatarem seu cotidiano e suas percepções. A forma como o enfermeiro recebe a formação sobre a sexualidade contribui para a construção/reconstrução de representações que estarão presentes na prática profissional, do mesmo modo como a reflexão acerca da prática poderá promover a mudança (CARTEIRO; NÉNÉ, 2015).

Em contraponto, alguns participantes relataram não sentir necessidade de abranger esses temas durante a graduação, visto que se deve tratar o usuário em sua totalidade. Uma alternativa aos interessados em refletir acerca da homo e da bissexualidade feminina seria a busca pessoal do conhecimento, a partir de iniciativa própria. A visualização e a aplicabilidade do que é construído em sala de aula favorece a compreensão do processo de educar/cuidar, tendo em vista que o conhecimento precisa representar significado para que o discente realize relações teórico-práticas, na medida em que ele é corresponsável pela consolidação do conhecimento (FIGUEIROA et al., 2017).

Considerando que a população de mulheres lésbicas e bissexuais muitas vezes não tem visibilidade quanto à sua orientação sexual, sendo rotulada como heterossexual, compreende-se a necessidade de se abordarem esses temas durante a formação, pois muitos cuidados devem ser adaptados às condições individuais de cada usuário.

O estudo apresenta como limitações o fato de ter explorado apenas a perspectiva dos discentes de enfermagem, não contemplando os docentes que participam do processo de ensinoaprendizagem, nem as usuárias lésbicas e bissexuais que vivenciam o cuidado recebido dos profissionais e discentes de enfermagem. Ademais, considerando que o assunto aborda um tema ainda cercado de tabus e pré-conceitos, compreende-se que pode ter havido constrangimento e inibição para dialogar acerca da temática, com consequente limitação da fala quanto à percepção dos participantes sobre o assunto.

A realização deste estudo pretende contribuir na identificação de potencialidades e fragilidades na formação acadêmica dos futuros profissionais enfermeiros quanto à temática da homossexualidade e bissexualidade feminina, proporcionando uma reflexão sobre o tema no que tange à formação do enfermeiro e seu impacto na qualidade da assistência prestada a essa população. Assim, em tempos de construção das novas diretrizes curriculares para a enfermagem, faz-se necessário incluir as discussões neste processo, visando fortalecer a formação na área.

Espera-se que, a partir dos achados apresentados, novos estudos possam ser desenvolvidos com vistas à promoção de estratégias de ensino-aprendizagem que fomentem o pensamento crítico e reflexivo dos discentes frente ao cuidado integral às mulheres lésbicas e bissexuais. Em tempos de expansão da produção tecnológica, o desenvolvimento e a validação de tecnologias podem se apresentar como uma estratégia potencialmente resolutiva para esta demanda. Nesta perspectiva, é preciso inserir as participantes nesse processo de construção, a fim de propor produtos ou processos tecnológicos aplicáveis e consumíveis tanto pelas instituições formadoras quanto pelos serviços de saúde.

\section{CONSIDERAÇÕES FINAIS}

O presente estudo possibilitou identificar que o cuidado às mulheres lésbicas e bissexuais apresenta influências sociais, culturais e particulares de cada discente. A vivência pessoal do discente, somada às oportunidades na universidade e com sua corresponsabilização pela formação, consolidam subsídios para o atendimento dessa população. Também foi possível identificar que, ainda que a formação mostre alguns avanços quanto à abordagem dessa temática na formação, continua a apresentar algumas fragilidades e desafios que podem ser minimizados por meio de uma construção coletiva, que repense e reformule a disposição das disciplinas por meio da inserção da presente temática. 
Dessa forma, identifica-se a necessidade de ampliação da reflexão acerca do tema no meio acadêmico, a fim de formar enfermeiros generalistas preparados e seguros para realizar o cuidado adequado às mulheres lésbicas e bissexuais, atendendo às suas especificidades. Assim, será possível um entendimento solidificado sobre as diversidades, promovendo um cuidado de enfermagem igualitário e sem discriminações.

\section{REFERÊNCIAS}

ARAÚJO, Luciane Marques $e t$ al. The care to lesbian women in the field of sexual and reproductive health. Rev enferm UERJ, Rio de Janeiro, v. 27, e34262, 2019. Disponível em: http://dx.doi.org/10.12957/reuerj.2018.34262. Acesso em: 17 fev. 2021.

BARDIN, Laurence. Análise de conteńdo. São Paulo: Edições 70, 2016.

BELÉM, Jameson Moreira et al. Atenção à saúde de lésbicas, gays, bissexuais, travestis e transexuais na estratégia saúde da família. Rev. Baiana Enferm, v. 32, e26475, 2018.

BRASIL. Ministério da Educação. Conselho Nacional de Educação. Resolução n ${ }^{\circ}$ 3, de 7 de novembro de 2001. Institui as Diretrizes Curriculares Nacionais do Curso de Graduação em Enfermagem. Brasília, 2001. Recuperado em 20 de junho de 2019. Disponível em:

http://portal.mec.gov.br/cne/arquivos/pdf/CES03.pdf. Acesso em: 17 fev. 2021.

BRASIL. Ministério da Saúde. Politica Nacional de Saúde Integral de Lésbicas, Gays, Bissexuais, Travestis e Transexuais. Brasília, 2013. Recuperado em 11 de junho de 2019. Disponível em:

http://bvsms.saude.gov.br/bvs/publicacoes/politica_nacional_saude_lesbicas_gays.pdf. Acesso em: 17 fev. 2021

BUTLER, Judith. Problemas de gênero: Feminismo e subversão da identidade. 15. ed. Rio de janeiro: Editora Civilização Brasileira, 2017.

CARTEIRO, Dora; NÉNÉ, Manuela. A importância da formação na área da sexualidade em enfermagem. Rev Associação Portuguesa Enfermeiros Obstetras, v. 16, p. 1646-3625, 2015.

CONSELHO FEDERAL DE ENFERMAGEM. Resolução n 564/2017. Aprova o novo Código de Ética dos Profissionais de Enfermagem. Brasília, 2017. Dísponível em: http://www.cofen.gov.br/resolucao-cofen-no-5642017_59145.html. Acesso em: 25 jun. 2019.

COSTA, Ângelo Brandelli; NARDI, Henrique Caetano. Homofobia e preconceito contra diversidade sexual: debate conceitual. Temas psicol., Ribeirão Preto, v. 23, n. 3, p. 715-726, set. 2015.

FIGUEIROA, Maria das Neves et al. A formação relacionada com a sexualidade humana na perceção de estudantes de enfermagem. Rev. Enf. Ref., Coimbra, v. serIV, n. 15, p. 21-30, dez. 2017.

FREITAS, Natália O.; SOUZA, Josueida C.; ARAÚJO, Ednaldo C. Lesbianismo e pesquisa em enfermagem: novos desafios. Rev. enferm. UFPE on line, v. 9 (Suppl. 6), p. 108-13, 2015.

GREENE, Meredith et al. Comparando a preparação de estudantes de medicina, odontologia e enfermagem para abordar a saúde de lésbicas, gays, bissexuais, transgêneros e queer. PLOS ONE, v. 13, n. 9, e0204104, 2018.

LOURO, Guacira Lopes. O corpo educado: pedagogias da sexualidade. 4. ed. Belo Horizonte: Autêntica, 2018. 
NAMA, Nassar et al. Medical students' perception of lesbian, gay, bisexual, and transgender (LGBT) discrimination in their learning environment and their self-reported comfort level for caring for LGBT patients: a survey study. Med Educ Online, v. 22, n. 1, 1368850. 2017.

ORTEGA, Maria del Carmen B. et al. Formação acadêmica do profissional de enfermagem e sua adequação às atividades de trabalho. Rev. Latino-Am. Enfermagem, Ribeirão Preto, v. 23, n. 3, p. 404410, jun. 2015.

PINHEIRO, Roseni. Integralidade em Saúde. In: PEREIRA, Isabel B.; LIMA, Júlio César F. (Orgs.). Dicionário da Educação Profissional em Saúde. Rio de Janeiro: EPSJV, 2008. p. 255-262. Disponível em: http://www.pucsp.br/prosaude/downloads/bibliografia/integralidade_em_saude.pdf. Acesso em: 17 fev. 2021.

PINTO, Diana; NOGUEIRA, Conceição. Portuguese nursing students' attitudes towards lesbians: from prejudice to recommendations for change. Temas psicol., Ribeirão Preto, v. 24, n. 3, p. 805814, set. 2016.

POLIT, Denise F.; BECK, Cheryl T. Fundamentos de Pesquisa em Enfermagem: avaliação de evidências para a prática da enfermagem. 9. ed. Porto Alegre: Artmed, 2019.

REIS, Toni. Manual de Comunicação LGBTI+. 2018. Disponível em: https://unaids.org.br/wpcontent/uploads/2018/05/manual-comunicacao-LGBTI.pdf. Acesso em: 03 jun. 2019.

SILVA, Jonatan W. S. B. et al. Políticas públicas de saúde voltadas à população LGBT e à atuação do controle social. Rev Espaç. Saúde, v. 18, n. 1, p. 140-9, 2017.

SOUSA, Josueida C. Cuidados do enfermeiro à mulher lésbica na estratégia de saúde da família. Dissertação (Mestrado Acadêmico em Enfermagem). Recife: Universidade Federal de Pernambuco, 2015.

SOUSA, Patrícia J. et al. Humanization on the embracement of lesbians, gays, bisexuals, transvestites and transsexuals in primary care: bioethical thoughts for nursing. Rev enferm UFPE on line., v. 5, n. 4, p. 1064-071, jun. 2011. Disponível em: https://doi.org/10.5205/reuol.1302-9310-1-LE.0504201128 Acesso em: 17 fev. 2021.

VITIRITTI, Bruno; ANDRADE, Sônia M. O.; PERES, José E. C. Diversidade sexual e relações profissionais: concepções de médicos e enfermeiros. Temas psicol., Ribeirão Preto, v. 24, n. 4, p. 13891405, dez. 2016.

Submetido: $25 / 11 / 2020$

Aprovado: 10/03/2021 